\title{
Implementation of a circuit of palliative care in patients with advanced lung diseases.
}

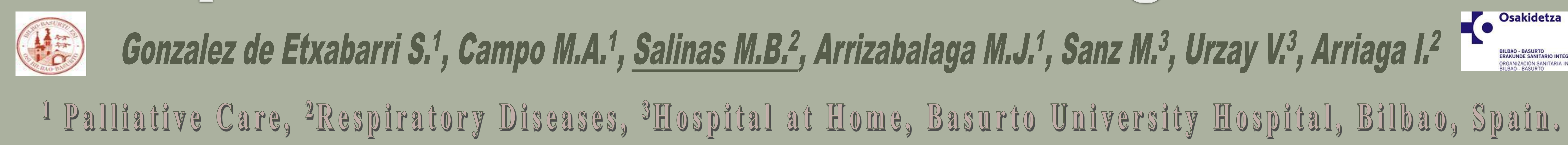

\section{Background}

Interstitial lung diseases(ILD), especially Idiopathic pulmonary fibrosis(IPF) have high morbidity, mortality, short survival and great impact on the quality of life, needing early palliative care but most die in a hospital and a minority receives palliative care.

\section{Aim}

Palliative care may reduce symptom burden in patients with ILD. This study aims to describe how do we perform palliative care support until the death in patients with ILD. The timing of referral for palliative care and the location of death.

\section{Matcria and methods}

Since October 2015, all patients with symptomatic ILD or with MRC 3-4 were referred to Palliative Care Unit(PCU). We have made a retrospective review of the clinical histories analyzing symptom control, the moment of the referral to PCU, admission or control needs in the hospital at home and the place of death.

63 patients(33 M-30 F), with advanced disease or MRC 2(4), MRC 3(5), MRC 4(54).Average age 79 years(62-95).

\section{Results}

PALLIATIVE CARE CIRCUIT IN ILD

ILD Respiratory monographic consultation

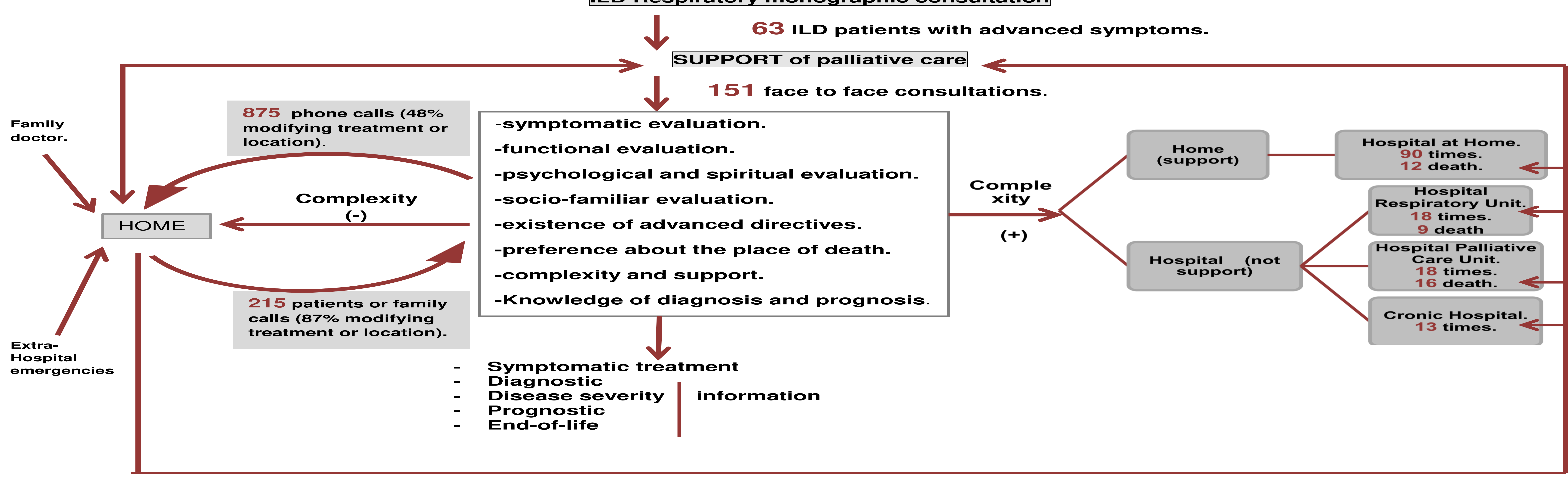

MAIN DISEASES

Idiopathic pulmonary fibrosis

\begin{tabular}{|c|c|}
\hline Idiopathic pulmonary fibrosis & $\begin{array}{c}31 \\
\begin{array}{c}\text { (17 with antifibrotic } \\
\text { treatment) }\end{array}\end{array}$ \\
\hline Conbined pulmonary fibrosis and emphysema & 8 \\
\hline Idiopathic nonspecific interstitial pneumonia & 6 \\
\hline Occupational exposure pulmonary fibrosis & 5 \\
\hline Chronic hypersensitivity pneumonitis & 4 \\
\hline Familial pulmonary fibrosis & 2 \\
\hline $\begin{array}{c}\text { Subacute or intermittent hypersensitivity } \\
\text { pneumonitis }\end{array}$ & 2 \\
\hline Non filiated ILD & 2 \\
\hline Desquamative interstitial pneumonia & 1 \\
\hline $\begin{array}{l}\text { Interstitial pneumonia with autoinmune features } \\
\qquad \text { (IPAF) }\end{array}$ & 1 \\
\hline
\end{tabular}

\section{FOLLOW-UP}

$\square$ 1- 25 months in patients whe are alive (median $12 \mathrm{~m}$.).

$\square$ 1- 18 months in the dead (median $5 \mathrm{~m}$.).
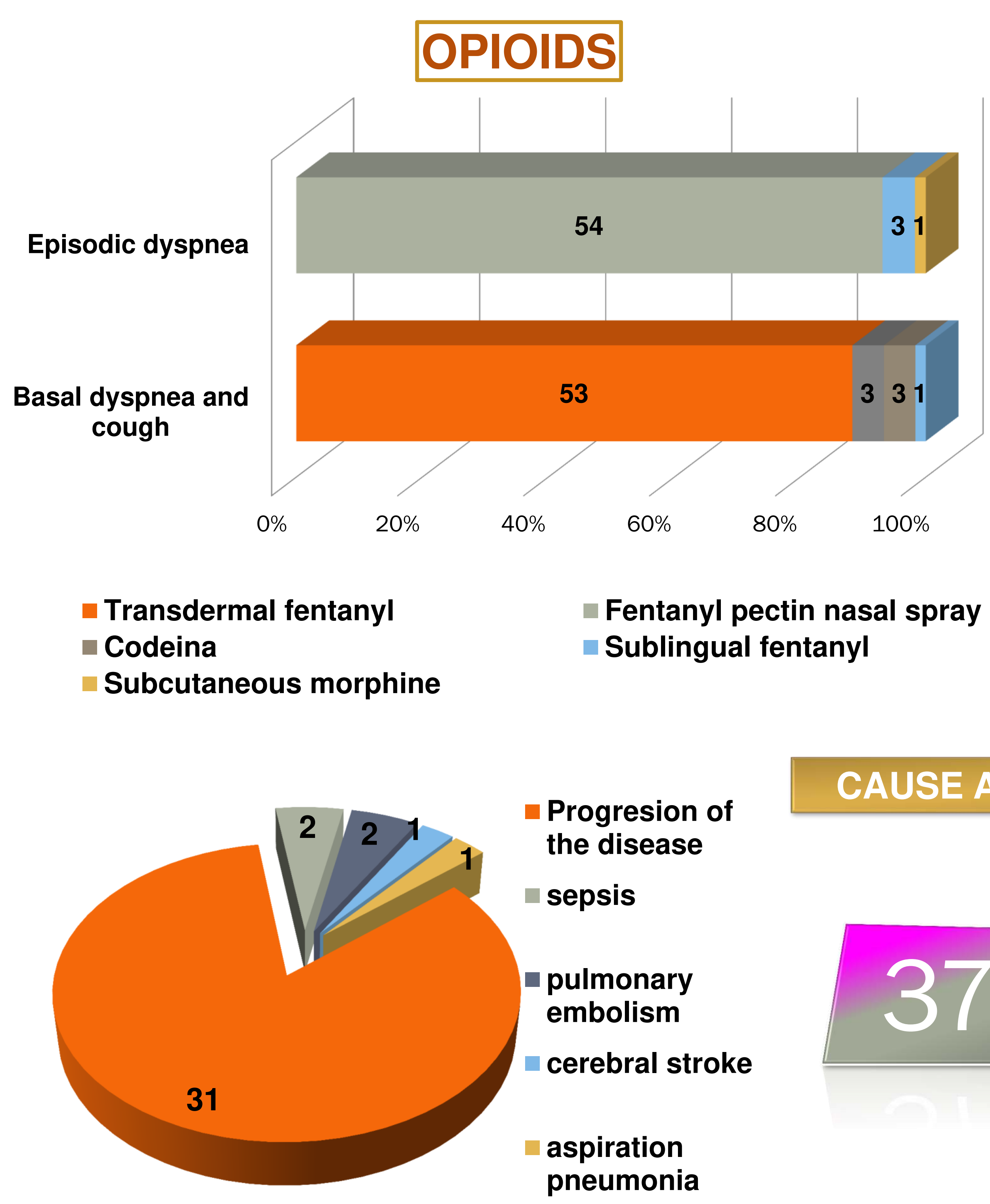

\section{CAUSE AND PLACE OF DEATH}
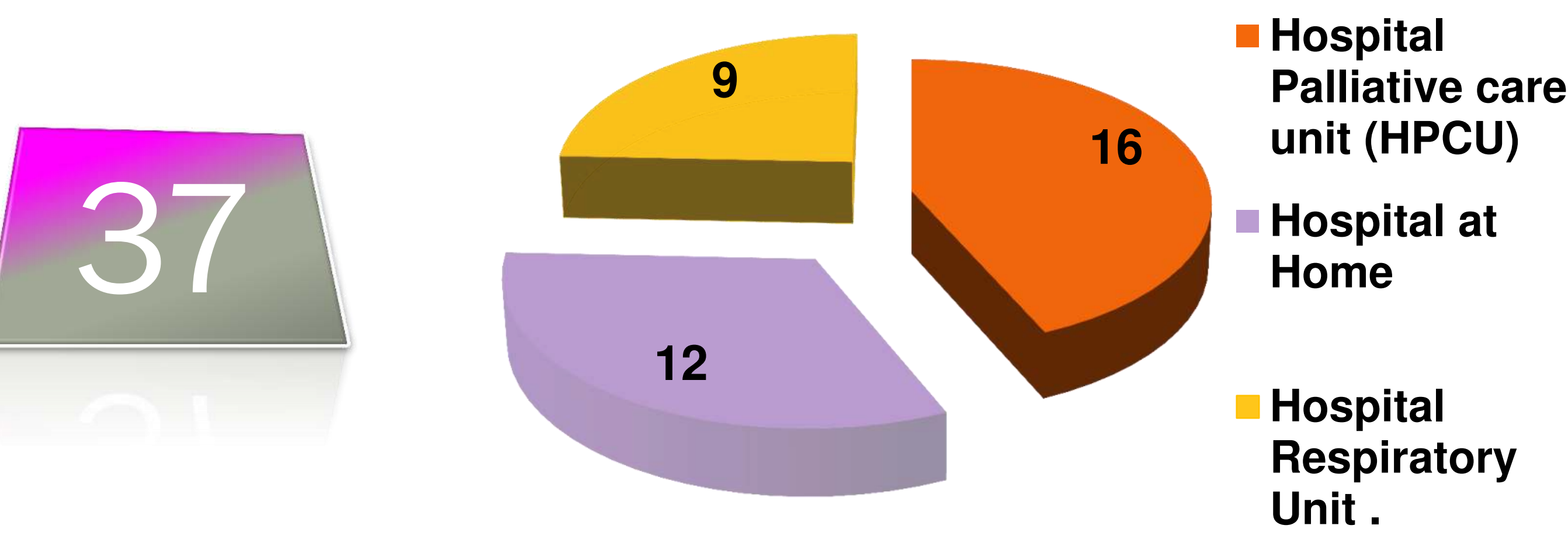

\section{Conclusion}

$\checkmark$ Palliative care in the ILD should be started early, at the occurrence of symptoms, they be continued through treatment, follow-up care and the end of life.

$\checkmark$ The establishment of the follow-up of patients with ILD for palliative care has made it possible to progress in the symptomatic control and achieve that $100 \%$ they died under palliative care, $44 \%$ in HCPU, $32 \%$ at home and $24 \%$ in the Hospital Respiratory Unit with support of Palliative Care. 